\title{
Swine Husbandry Practices in Ethiopia: A Review
}

\author{
Eyob Gebregziabhear \\ Ethiopian Agricultural Research Institute, Debre Zeit Center, P.O.Box 32, Debre Zeit, Ethiopia
}

\begin{abstract}
In Ethiopia, swine are mainly raised under small scale production systems of urban and peri-urban areas. The swine sector has got very little attention compared to other livestock components. This happened mainly due to religious and social reasons. Swine breeds in Ethiopia consist of exotic breeds and their crosses. The indigenous pig is an animal which has been very neglected and wild. Although smallholder swine farmers make a contribution to the livestock sector, they are discouraged and constrained by issues relevant to culture and religion, in addition to feed shortage, disease, inaccessible market, lack of clear pig and pork marketing system, lack of transport, poor extension and veterinary services, lack of market and shortage of land as the major constraints of swine production and marketing in Ethiopia. This paper highlights the Ethiopian swine industry, the role played by the smallholder swine farmers, the constraints and recommendations to the policy makers and stakeholders on the way of promoting smallholder swine farmers.
\end{abstract}

Keywords: constraints, government, swine production

DOI: $10.7176 / \mathrm{JBAH} / 12-1-03$

Publication date: January $31^{\text {st }} 2022$

\section{INTRODUCTION}

Ethiopia has around 28 thousands swine which represent $0.1 \%$ of African swine population (FAO, 2005) and they are 100 percent exotic breeds and not yet characterized very well. Moreover, the domestic pig has been very much neglected by the community (Yeshambel and Bimerew, 2014). The exotic swine are integrated into the traditional mixed farming system with the purpose of income generation. Inadequate provision for confinement and extensive management based on scavenging was the most commonly practiced management practice (Abdu and Gashaw, 2010; Theodros et al., 2013). Although the swine sector has not been well advanced in African countries like in Ethiopia, it has the potential to contribute to the food security and create job opportunities especially for the poor farming communities (Petrus et al 2011; Amills et al 2013; Tekle et al 2013; Berihu et al 2015; Birhan et al 2015; Goraga et al 2015; Greve, 2015; Adeoye et al., 2016; Goraga et al., 2016). As swine production is at its infant stage in Ethiopia, it is challenged by several bottlenecks (Tekle et al 2013; Berihu et al, 2015; Birhan et al 2015; Goraga et al 2015 \& 16). Although there is no policy preventing investment in the swine sector in Ethiopia, so far less attention has been given to the sector and there is poor public awareness on its socio-economic advantages. Furthermore, most livestock producers in Ethiopia do not have keen interest to invest in swine sector compared with their interest to invest in other livestock sectors, and this could be partly associated with the lack of functional marketing systems for live pigs and pork, and also due to the religious taboos against swine production and pork consumption in the country (Goraga et al., 2015 \& 16). In many rural parts of Ethiopia, pig production was characterized by extensive production system whereby pigs are allowed to scavenge in the backyard and at municipal garbage dumping sites (Abdu and Gashaw, 2010).

According to Ethiopian Livestock Development Master plan (MoARD 2007), all the pig population in Ethiopia has been under private ownership and in strictly religious terms members of the Ethiopian Orthodox Church as well as followers of the Islamic faith are not in favor of consuming pork. Hence, there is very limited pork market within Ethiopia and in those surrounding Islamic countries. Furthermore, no public intervention has been promoted on pig production in Ethiopia (MoARD 2007). The domestic pig is an animal which has been ignored by farmers and the scientific community in Ethiopia.

However, there are limited researches and survey works have been done on swine production, management, market and constraints of these pig producers in the study area. As a result, there is limited information on the performance of swine production and marketing in the country.

\section{MATERIALS AND METHODS}

A comprehensive internet search of literature on small scale cattle fattening as well as on commercial feedlot enterprises in Ethiopia was undertaken using Google Search. Literature referred was analyzed in pros and relevant cited tables and figures adopted.

\section{Socio-Economic Characteristics of Pig raising farmers}

Seventy eight percent of the pig producing households in Mekelle town and southern Tigray were having elementary school and above educational background. (Tekle et al., 2013). Similarly, Yeshambel and Bimerew (2014) reported that the majority of pig keepers in Mecha District of Amhara Region were literate people from 
read and write up to diploma level $(80 \%)$. About $48.4 \%$ and $21 \%$ of the respondents attended high school to college and university to above, respectively (Gorega et al., 2016a). According to Mekuriaw and Asmare, (2014) most of the pig keepers in Northwestern Ethiopia were engaged in a variety of off-farm activities with livestock fattening being the highest $(33.2 \%)$ followed by trade $(20 \%)$ and office work $(13.4 \%)$. Contrary to these major findings, according to Mekuriaw and Asmare (2014), 20\% of swine producers were illiterate and while 53\% of them have attended elementary education and above. The gross income of the swine producers was significantly different among the three scales of production where they had 2662, 5629, and 41764 USD per year in small, medium and large scale production, respectively. The major income sources were pig production, nonagricultural activities and crop-livestock production (Figure 4). Similarly, a separate study by Mekuriaw and Asmare (2014) found that Ethiopian swine producers who live in Mecha District, Amhara Region get income from livestock fattening $(33.2 \%)$, dairy $(6.7 \%)$, trade $(20 \%)$ and office work $(13.4 \%)$.

\section{Swine Production Systems in Ethiopia}

Mode of swine production is broadly classified into free-range scavenging, semi-intensive and intensive pig keeping (CTA 2011). The majorities of pig producer $42.8 \%$ were semi intensive production system and followed by two production system (extensive 28.6\% and intensive 28.6\%) in Debre Markos town (Embet et al 2017). In many rural parts of Ethiopia, pig production was characterized by extensive production system whereby animals are allowed to scavenge in the backyard and at municipal garbage dumping sites (Yeshambel and Bimrew 2013). According to Tewodros et al (2010), pig production was integrated into the traditional mixed farming system. In addition to pig, $94 \%$ of the producers were keeping at least one species with pigs involving cattle, sheep, goats or chicken. Similarly, Abdu and Gashaw (2010), reported that $24 \%$ of the farms visited in central Ethiopia were under mixed farming system. Integration of pigs into the traditional mixed farming system with minimal inputs and poor managements (Tomass et al 2013). Generally, the swine production in Ethiopia is more related to smallholder operations characterized by small land holdings, low income, small herd size and adopting a mixed crop-livestock type of agricultural production system. (Gorega et al 2016). In contrast, the pig management system is also classified broadly into two groups: tethered/penned and stall-fed (Rameswar et al. 2007).

\section{Purpose of Pig Keeping}

The reasons for keeping swine are rational and are related to the producers' objective, culture and social tradition. Major reasons for keeping pigs in different towns of Ethiopia were to generate income (Bimerew and Yeshambel 2014, Gorga et al., 2016a, Mulugeta, 2016, Tekele et al. 2011 and Thedrose et al., 2013). In contrast to the situation in Namibia, Uganda, and Kenya where pig keeping is for income and pork consumption (Petrus et al. 2011; Muhanguzi et al. 2012). This in turn explains the lack of local market and in turn calls market orientation towards organized export market and value creation. Furthermore, small scale pig production has been indicated as a viable livestock system in many East African countries, playing an important role in pork production either for home consumption or sale and income generation (Wabacha et al 2004; Kagira et al 2010; Mutua et al 2011; Petrus et al 2011; Muhanguzi et al 2012; Riedel et al 2012).

\section{Breeds}

Yorkshire, Landrace, Duroc, Hampshire, Berkshire, Tibetan, Tamworth, Meishan and their crosses are the most common pig breeds in the world (FAO, 2009). According to Zemelak et al. (2017), the majority of the swine producers don't know their breed name and/or origin. The same author reported that the majority of the swine breeds found in Ethiopia are crossbreeds which are the crosses of two or more of the commercial breeds with Eurasian origin. White, black, brown and a mix of two or more colors were most popular swine's colors in Ethiopia (Thedrose et al.2013; Mulugeta, 2016; Zemelak et al. 2017).

Swine production and reproductive traits such as growth rate, age at puberty, age at first service, service per conception, age at first furrowing, furrowing interval, number of furrowing/sow/year, gestation period, litter size at birth, litter size at weaning, birth weight, weaning weight and mature weight were not well characterized as compared to ruminants.

\section{Feeding and nutrition}

Swine, pregnant sows and gilts, lactating sows, piglets, young and adult pigs should be fed, according to their needs (CTA 2011). Swine is omnivorous animal that can take advantage of a wide variety of feedstuffs. The major feed sources for swine production include household waste, grass, brewer's residue and commercial feed (Nath et al 2013) and kitchen waste, sorghum bran, rotten fruits and brewer's residue (Nsoso et al 2003). Likewise, pigs feed on cassava, potatoes and crop residues (sweet potato vines, banana peelings), grasses and ruminal contents from the local abattoirs (Dennis et al 2012). In urban areas, feed sources were kitchen and restaurant waste, and likewise crops and agriculture residues were in rural areas however, supplements and concentrates were used on a limited scale (Deny, 2012). Average feed intake DM basis of Piglets, weaned, 
growers, sows, boars and fatteners in Adama, Bishoftu and Addis Ababa were 0.18, 0.49, 0.69, 1.26, 1.28, $1.81 \mathrm{~kg}$, respectively (Mulugeta, 2016). The major feed resources of pig feeds as ranked by keepers in Mecha District were grazing (46.7\%) followed by crop residues $(26.7 \%)$ and household offal $(20 \%)$. According to Thedros et al (2015), pig production was based on scavenging and all pig owners let their pigs to scavenge on public garbage damping sites and pigs were commonly seen wandering along the streets in all the study areas. The type of feed available for swine in and around Holetta area was mainly oil seed cake and waste food. Some swine were also feed on pasture, crop residue, and garbage (Abdu and Gashaw, 2010). Petrus et al (2011) reported that $98 \%$ of pig producers in Namibia fed their animals on home remnants and they allowed them to scavenge. And rural farmers fed their pigs what was available disregarding their age, sex and their production stages. Feed represents between $60 \%$ and $70 \%$ of the total cost of pork production in modern capital-intensive systems. Within feed, energy alone may represent 50\% or more of the total cost (Gutierrez and Patience 2012). Grazing and crop residues are the major feed resources and improved feed was the least available feed or livestock production in Ethiopia (Figure 1).

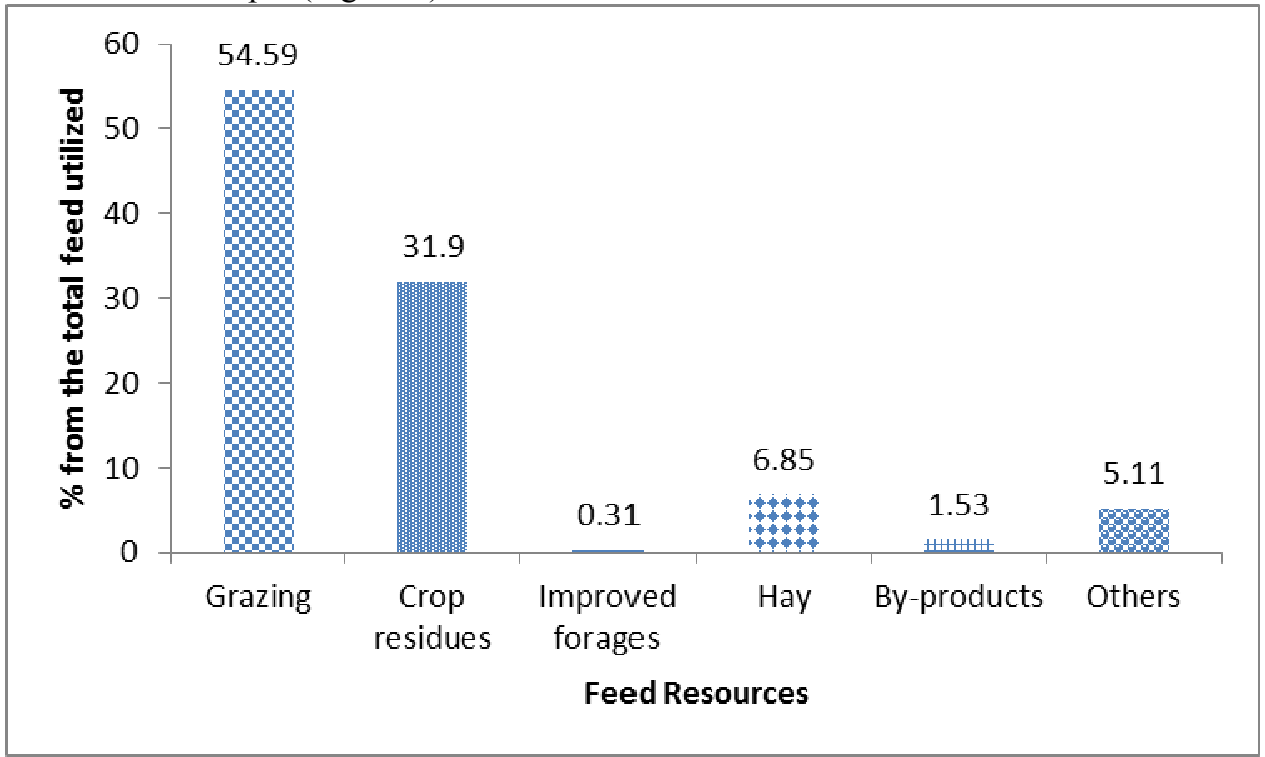

Figure 1: Livestock feed resources and proportion in Ethiopia (CSA 2017).

\section{Reproductive and Productive Performance of Pig}

The productive and reproductive performance of swine in Adama, Bishoftu and Addis Ababa were 4.6, 8, 2-3, 4 $8 \%$ respectively, and $0.71,6.2,63.6 \mathrm{Kg}$ for age at first service, age at first furrowing, furrowing interval gestation period, birth weight, weaning weight, and mature body weight respectively (Mulugeta 2016). The majority of pigs $(85.6 \%)$ give birth to their first piglet between 3-5 months of age, and $14.4 \%$ of the pigs give birth to their first piglet when they are five months or older than that. This shows good productivity and reproductivity of pigs in the study area. The age over half of the pigs $(57.1 \%)$ pelting the consecutive piglet ranges between 4-5 months, and the pigs pelting their consecutive piglet below and above 4-5 months are $42.9 \%$. This shows pigs are more productive than other livestock animals. The majority (85.7\%) of give birth to 10 to 15 piglets per sow, and $14.3 \%$ of the pigs give birth to below 10 piglets per sow, which is mainly for extensive production systems (Mulugeta, 2016).

Mutua et al (2011) in western Kenya who reported that sows can farrow at least two times in a year yielding multiple piglets at each farrowing, sows were 12.1 \pm 4.5 months old when they farrowed for the first time, average litter size was $7.8 \pm 2.6$ while piglets were weaned at $5.4 \pm 3.3$ weeks of age (Mutua et al 2011). This difference in production potential can be explained by breed variation.

Smallholder producers mainly keep exotic breeds, since consumers prefer pork from imported breeds. Farmers considered traits such as body size, shape, vitality of sows and availability of replacement stock when choosing replacement boars. Research in India indicated that $87.5 \%$ upgraded pigs were more suitable for smallholder producers than pure Hampshire or Large Black or 75\% upgraded pigs (Das et al 2005). 
Table 1. Parameters and the mean values of exotic pig traits

\begin{tabular}{|l|l|l|l|}
\hline Parameters & Mean values & Rearing systems & Sources References \\
\hline Gestation period (days) & 115 & Semi-intensive & Mulugeta, 2016 \\
\hline Mature body weights(Kg) & $77-89$ & Semi-intensive & Gorga et al., 2017 \\
\hline Dressing percentage & $69.4-84.7 \%$ & Semi-intensive & Embet et al. (2017) \\
\hline Age at $1^{\text {st }}$ farrowing(months) & 8 & Semi-intensive & Thedrose et al.(2013) \\
\hline Farrowing interval(months) & $4-5$ & Semi-intensive & Embet et al. (2017) \\
\hline Litter weight at birth(Kg) & 0.8 & Semi-intensive & Chabo et al. (2000) \\
\hline Birth weight(Kg) & 0.71 & Semi-intensive & Mulugeta, 2016 \\
\hline Weaning weight(Kg) & 6.4 & Semi-intensive & Baffour-Awuah et al. $(2005)$ \\
\hline Weaning age(weeks) & $3-4$ & Semi-intensive & Mulugeta, 2016 \\
\hline Litter size & $8-13$ & Semi-intensive & Tekle et al. (2013) \\
\hline Mortality rate $(\%)$ & 20 & Semi-intensive & Yeshambel and Bimerew $(2014)$ \\
\hline Life span & 180 to 220 & Semi-intensive & Langkabel and Fries $(2013)$ \\
\hline
\end{tabular}

\section{Swine Health Care}

A herd health management practices include: vaccination, observation of all animals for injury or signs of disease, accurate and reliable record keeping, prevention, detection and treatment of disease or injury, pest control, animal handlers (Mulugeta, 2016). Parasitic infections were prevalent in pigs in Bishfotu town (Alemnesh et al 2015; Geresu et al., 2015; Seid and Abebaw 2002). Extensive husbandry system coupled with poor environmental hygiene and non-selective feeding behavior of pigs has been indicated as a major risk factor for infection of pigs with helminths and other gastrointestinal (GIT) parasites. Successful swine production requires the application of health-conserving, disease preventing, and parasite-controlling measures to the breeding, feeding, and managing of the herd. By nature, pigs possess clean habits. However, in many cases they are kept in old, crowded, and filthy quarters and such conditions favor the attack by the common diseases and parasites of swine (Michael, 1996).

According to Tomass et al (2013), the domestic pig has a role in the epidemiology of important zoonotic diseases such as Ascaris and Cryptosporidium spp and as a reservoir host of Fasciola hepatica, an economically important parasite of ruminants. Arega et al (2013) isolated M. tuberculosis, an emerging zoonotic disease, at prevalence rate of $5.8 \%$ in pigs slaughtered at two abattoirs in central Ethiopia, suggesting the existence of possible risk of interspecies transmission particularly between pigs and humans. This situation has to be taken as critical taking the association between TB and HIV (Arega et al 2013).

\section{Effect of Religion on Development of Swine Industry in Ethiopia}

Ethiopia has accepted Judaism 3000 thousand years ago when the Queen of Sheba visited King Solomon in Jerusalem. The country's culture has been heavily influenced by the Jewish culture since then and Old Testament rules and regulations which forbids eating pork as Swine are non-ruminants although their hooves are split.

The Holy Bible in Leviticus, chapter 11, verses 2 to 8 says, "Now the LORD spoke to Moses and Aaron, saying to them, "Speak to the children of Israel, saying, 'These are the animals which you may eat among all the animals that are on the earth: Among the animals, whatever divides the hoof, having cloven hooves and chewing the cud - that you may eat. Nevertheless these you shall not eat among those that chew the cud or those that have cloven hooves: the camel, because it chews the cud but does not have cloven hooves, is unclean to you; the rock hyrax, because it chews the cud but does not have cloven hooves, is unclean to you; the hare, because it chews the cud but does not have cloven hooves, is unclean to you; and the swine, though it divides the hoof, having cloven hooves, yet does not chew the cud, is unclean to you. Their flesh you shall not eat, and their carcasses you shall not touch. Pigs are not also considered as 'clean' animals by Islam. The Quran, chapter 2, verses 173 says, "He has only forbidden to you dead animals, blood, the flesh of swine, and that which has been dedicated to other than Allah". And as a result, most Ethiopians do not eat pork for religious reasons. Even the culture from Ethiopian Orthodox Church followers has influenced protestant Christians that most of them do not eat pork.

Pigs are believed to have been domesticated from wild boar as early as 9000 years ago because of their adaptive and dietary nature than other wild animals. They domesticated earlier than other forms of livestock, including cattle. They are originally native to Europe and parts of Asia but have, over the centuries, been introduced to many parts of the world. Pigs are naturally omnivores and will eat both plants and animals. Throughout history, animals, including pigs, have played an important role in human lives. In China, since ancient times, Chinese people have recognized animals as their properties, and animal husbandry has played important economic roles. Animal meat, especially pork and pork products is a main source of food for Chinese people. However at the beginning, the relationship between humans and animals is affected by culture and religion in china with both Islamic and Christian followers. In Ethiopia, a pork market at local level is not 
expected and it needs further strong awareness.

\section{Pig Marketing Practices}

In Ethiopia, almost no information is available on marketing of pigs, except little information provided by few authors (Berihu and Tamir 2016). Pig and pork marketing in Ethiopia have not been well developed. This is mainly due to religion, social and cultural reasons. Most of Ethiopians are either followers of the Ethiopian Orthodox Church or Islam and they are not allowed to eat pork. The main reason for keeping pigs in Ethiopia is to earn money from the sale of live pigs (Goraga et al 2017b). Neither hotels nor butchers sell pork. Whereas in supermarkets mortadella, salami, sausage and raw cuts (rarely available) are sold with other meat types. In the western areas of Kenya, pig butchers slaughter pigs and produce marketable pork (Levy et al., 2014). Unlike in Ethiopia, live pigs are sold at local village markets to intermediate traders in Nigeria where the pig marketing channel follow a centralized pattern in which pig farmers (producers) bring pigs together in larger central and terminal markets (Ajala and Adesehinwa, 2008). Berihu and Tamir (2016) report five different marketing agents (pig producers, traders, supermarket owners, restaurant owners/hoteliers) participate in pig marketing channels in Ethiopia where traders are the main suppliers of pigs to the market. Traders sold their pigs to restaurants, hotels, supermarkets and consumers.

Pigs are generally traded by weighing and 'eye-ball' pricing, is uncommon in pigs. Pigs are sold on a perhead basis and price agreement reached by a long one-on-one bargaining between a seller and a buyer. Under such circumstances, prices paid reflect buyers' preference for various animal characteristics (weight, sex, age, condition, breed, and color), the purpose of animals purchased (for resale, slaughter, fattening or reproduction), the season of the year (occurrence of religious and cultural festivals) and the bargaining skills of buyers and sellers (Kebede 1992; Ehui et al 2000).

\section{Pork Consumption Patterns}

In Ethiopia, a number of foreigners living and working in the country buy and consume pork. According to Goraga et al. (2017a), Asians and Europeans are the major pork consumers in the country. The same author reported that, pork is mainly consumed by youth and adult age groups. In terms of religion, Protestant and Catholics are the major pork consumers.

Table 2 Consumption of pork and other livestock meat for African countries (kg/capita, 2018)

\begin{tabular}{|l|l|l|l|l|}
\hline Country/Location & Beef and Veal & Pork Meat & Poultry meat & Sheep meat \\
\hline Algeria & 3.9 & 0.1 & 6.3 & 7.1 \\
\hline Egypt & 9.3 & 0.2 & 9.2 & 1.3 \\
\hline Ethiopia & 2.4 & 0.0 & 0.5 & 1.2 \\
\hline Ghana & 0.8 & 0.8 & 6.1 & 1.5 \\
\hline Nigeria & 1.6 & 1.1 & 0.9 & 2.3 \\
\hline South Africa & 11.0 & 3.4 & 32.8 & 3.0 \\
\hline Zambia & 9.0 & 1.5 & 2.6 & 0.5 \\
\hline
\end{tabular}

Source: OECD/FAO (2018)

\section{Constraints and Opportunities}

Pig production and productivity in Ethiopia is constrained by many factors. According to Tekele et al. (2013), the major constraints to pig production in Mekelle and southern Tigray region reported according to their order of importance include poor marketing opportunities, increasing feed cost, lack of basic knowledge on pig management practices, poor extension service, lack of skilled veterinarians on pig diseases and poor preventive health care. Similar production constraints were reported by Muhanguzi et al (2012) in Uganda; by Petrus et al (2011) in Namibia; by Kagira et al (2010) in western Kenya. Petrus et al (2011) generalized that smallholder farmers in the developing world have limited expertise resulting in poor management and planning of pig enterprises. The production constraints might hinder improvement to productivity of pigs (Wabacha et al 2004). According to Ayele et al (2003), alleviating constraints to marketing, improving marketing and market information and upgrading marketing infrastructures will potentially increase the welfare of smallholder producers and urban consumers and improve the national balance of payments. The government should also work on cultural and behavioral change of the people and also formulate an appropriate policy regarding swine production without delay, and should include it in the national livestock development program (Abdu and Gashaw 2010).

There are several characteristics that make swine the choice of farm animals at smallholder farmers level in Africa. Pigs grow faster compared to beef cattle. They have higher reproductive performance and better feed conversion. The production cost is relatively lower for pig production compared to beef cattle; it can take advantage of a wide variety of feedstuffs. Pigs have higher carcass percentages as compared to beef cattle. Therefore, all those advantages can make swine the choice of farm animals that can best fit to African's livestock 
production systems and quickly respond to food demand in the continent. According to Gorga et al (2015/2016) and Shambel and Bimerew (2015), smallholder swine producers have increased from time to time.

Ethiopia has some of the important opportunities influencing the meat and live animals industry, particularly the export sector (Ameha, 2011). The country has large livestock population with diverse and adaptable genotypes; diverse agro-ecologies for production of different types of livestock; government interest support to the livestock industry; increasing number of export abattoirs and live animal exporters; the expansion of agro-industries and the increase of by-product feedstuffs allowing for enhanced productivity; proximity to Middle Eastern countries and adaptation of importing countries to the taste of Ethiopian animals; and high demand for meat and live animals including the domestic market. There is a large potential to expand Ethiopian exports to the Middle East if the value chain actors in Ethiopia meet export market standards.

\section{Conclusion}

Swine production is a recently introduced activity in Ethiopia with traditional management based on scavenging type of feeding. Semi-intensive swine production system is popular in the country with poor swine husbandry practices such as feeding, breeding, housing, health care, marketing and overall management efforts. The pig and pork market constraints in Ethiopia includes: lack of clear pig and pork marketing system, factors of culture and religion, inaccessibility of market and lack of transport, lack of effective extension service to use newer technologies and practices and lack of market information. On the other hand, some of the opportunities in pig and pork marketing include alarming population growth, infrastructure development, urbanization, and increase in income and government focus, accessible technology for intervention, modern input and educated manpower. Meat and live animal marketing constraints include: lack of clear marketing channels, lack of inclusive market information, seasonal based demand, long market chain, lack of market oriented production, lack of market information and poor market infrastructure and preferences and export trends and preferences.

\section{Recommendations}

$>$ The swine found in the country are a mixture of different exotic swine breeds. Therefore, for accurate identification phenotypic and molecular characterization is required

$>$ Research centers, Ministry of Agriculture and stakeholders working in the agricultural production packages must work together to increase the production and productivity of the swine keepers, which can finally contribute to the overall economic development of the the country.

$>$ The government of Ethiopia instituting policies that support smallholder swine producers by facilitating the extension, research, development, market structure and investment.

\section{CONFLICT OF INTERESTS}

The author has not declared any conflict of interests

\section{ACKNOWLEDGMENT}

I am deeply grateful and indebted to the authors for their 'efforts in correcting and editing of this manuscript.

\section{References}

Abdu S and Gashaw A 2010 Production system dynamism and parasitic interaction of swine in and around Holetta, Ethiopia. Ethiopian Veterinary Journal, 14: 71-81.

Ajala MK, Adesehinwa AOK 2008. Analysis of Pig Marketing in Zango Kataf Local Govern- ment Area of Kaduna State, Nigeria. TROPICULTURA, 26(4): 229-239

Alemnesh J., Nesibu A.l, Fanos T., Yisehak T., and Birhanu H. 2015.Parasites of pigs in two farms with poor husbandry practices in Bishoftu, Ethiopia. Onderstepoort J Vet Res., 82(1): 839

Ameha S 2011. Export requirements for meat and live small ruminants: How can Development agents assist producers to improve small ruminant export? Technical Tulletin No.47, Addis Ababa, Ethiopia.

Baffour-Awuah O., Kewuribi C. S. and Este D. B. 2005. The performance of Ashanti black pigs under an intensive management system. Ghanaian Journal of Animal Science, 1:713.

Berihu M, Tamir B, Lundeheim N 2015 Health Management and Factors Affecting Small Scale Intensive Pig Production in East Shewa of Central Ethiopia. Department of Animal Science, College of Veterinary Medicine and Agriculture. 9(5): 373-380.

FAO 2009 Farmer's Hand Book on Pig Production. Rome, Italy. Pp. 1 - 77

FAO 2019 The future of livestock in Ethiopia. Opportunities and challenges in the face of uncertainty. Rome. 48 pp. Licence: CC BY-NC-SA 3.0 IGO.

Berihu, M., \& Tamir, B. 2016 Marketing Practices and Constraints of Pig Production under Small Scale Intensive Farming in East Shewa, Ethiopia. Global Veterinaria, 16(3), 261-267.

Retrieved from https://www.idosi.org/gv/gv16(3)16/8.pdf 
Chabo P. and Babusi B. 2000 Pig productivity: A case study for South-Eastern Botswana. Department of animal science and production, Botswana College of agriculture private Bag 0027, Gaborone, Botswana. Livestock Research for Rural Development, 12 (3).

Dennis M., Vincent L., Frank N. M. 2012 Factors that influence pig production in Central Uganda -Case study of Nangabo Sub-County, Wakiso district. Veterinary World, 5(6): 346-351.

Emebet D, Awoke K, Asenakew A 2017 Challenges, Opportunities and Management Practice of Pig Production in Debre Markos Town, East Gojjam Zone in Amahra Regional State, Ethiopia. Poult Fish Wildl Sci 5: 176. doi: 10.4172/2375-446X.1000176

Gutierrez NA, Patience JF, 2012 The metabolic basis of feed-energy efficiency in swine. In Proc Al Leman Conference. Veterinary Continuing Education. University of Minnesota. St. Paul, MN;19-26.

Goraga, Z. S., Tekletsadik, E., Abyi, S., Mengesha, M., \& Gustavo, L. J. M. M. 2017a. Characterization of Pork Consumers and Preference for Quality Traits in Ethiopia. World

Journal of Dairy \& Food Sciences, 12(2), 79-86. Retrieved from https://idosi.org/wjdfs/wjdfs12(2)17/2.pdf

Goraga, Z., Bekele, A., Degefa, T., Alwi, M., Mengesha, M., \& Gustavo, L. J. M. M. 2017b Live Pigs Marketing and Buyers' Characteristics in Ethiopia. ARJASR, 5(4), 244-254.

Retrieved fromhttps:/www.academicresearchjournals.org/ARJASR/Abstract/2017/July/Goraga\% 20et\%20al.Htm

Goraga, Z. S., Mengesha, M., Miele, M., \& Gustavo, L. J. M. M.2016a Swine production in Ethiopia: I. Socioeconomic characteristics of producers and motivational drivers. Glob. J. Agri. Agri. Sci., 3(7), $279-287$. Retrieved from http://www.globalscienceresearchjournals.org/gjas/964102015792

Kagira J M, Kanyari P W, Maingi N, Githigia S M, Ng'ang'a J C and Karuga J W 2010 Characteristics of the smallholder free-range pig production system in western Kenya. Trop. Anim. Health Prod. 42 (5): $865-$ 73. doi: 10.1007/s11250-009-9500-y.

Levy, M. A., Dewey, C. E., Poljak, Z., Weersink, A., \& Mutua, F. K. 2014 Comparing the operations and challenges of pig butchers in rural and peri-urban settings of western Kenya. African J. Agri. Res., 9(1), 125-136. https://dx.doi.org/10.5897/AJAR12.2174

Malede Birhan, Tamene Gemechu and Betelhem G/medhin 2015. Challenges and Opportunities of Pig Farming and Feeding Strategy in Gondar Town, Ethiopia Academic Journal of Nutrition 4 (2): 84-89.

Michael T.H. 1996 Swine management manual. Land grant institutions of the pacific, Agricultural development in the American pacific, ADAP 96-4

Muhanguzi D, Lutwama V and Mwiine F N 2012 Factors that influence pig production in Central Uganda Case study of Nangabo Sub-County, Wakiso district, Vet World, 5 (6): 346-351.doi: 10.5455/vetworld.2012.346-351.

OECD/FAO (2018). OECD-FAO Agricultural Outlook 2018 - 2027 Food and Agriculture Organization (FAO), Viale delle Terme di Caracalla, 00153 Rome,Italy.

Geresu MA, Hailemariam Z, Mamo G, Tafa M, Megersa M 2015 Prevalence and Associated Risk Factors of Major Gastrointestinal Parasites of Pig Slaughtered at Addis Ababa Abattoirs Enterprise, Ethiopia. J Veterinar Sci Technol 6: 244. doi: 10.4172/2157-7579.1000244

Goraga Z, Bekele A, Degefa T, Alwi M, Mengesha M, Lima GJMM 2017 Live Pigs Marketing and Buyers' Characteristics in Ethiopia. Acad. Res. J. Agri. Sci. Res. 5(4): 244-254

Mulugeta Berihu 2016 Pig production under small scale intensive farming in east Shewa of central Oromia, Ethiopia: management, feed resources, performance and marketing practices PhD Dissertation Addis Ababa University, Addis Ababa.

Mutua F K, Dewey C E, Arimi S M, Schelling E, Ogara W O and Levy M. 2011. Reproductive performance of sows in rural communities of Busia and Kakamega Districts, Western Kenya, African Journal of Agricultural Research, 6(31), 6485-6491.

Nath P. K., Ngachan S. V., Tripathi A. K. and Mohanty A. K. 2013 Characterization of smallholder pig production system: productive and reproductive performances of local and crossbred pigs in Sikkim Himalayan Region. Tropical Animal Production and Health, 45:1513-1518.

Nsoso S. J., Mosweu S., Malelaand L. and Podisi B. 2003 A survey on population, distribution, management and utilization of indigenous Tswana pigs in Southern Botswana. Animal Genetic Resource Information, 34:83- 96.ftp://ftp.fao.org/docrep/fao/007/y5303t/y5303t10.pdf

Petrus N P, Mpofu I, Schneider M B and Nepembe M 2011. The constraints and potentials of pig production among communal farmers in Etayi Constituency of Namibia. Livestock Research for Rural Development, 23 (159). Retrieved June 26, 2013, at: http://www.lrrd.org//rrd23/7/petr23159.htm

Rameswar D., William T., Lucila L. M. and Anjani K. 2007 Kokrajhar's pig sub-sector: current status, constraints and opportunities. Project report

Riedel S, Schiborra A, Huelsebusch C, Huanming M and Schlecht E 2012 Opportunities and challenges for smallholder pig production systems in a mountainous region of Xishuangbanna, Yunnan Province, China. 
Trop Anim Health Prod., 44:1971-1980.

Theodros T., Abreha T.and Tsegabirhan K. 2013. "Smallholder swine production and its constraints in Mekelle and southern zone of Tigray region, north Ethiopia," Livestock Research for Rural Development, vol. 25, no. 10, 2013.

Teklu Gebretsadik, Dinku Negash, Bereket Zeleke, Tekleyohannes Berhanu, Asrat Tera, Tona Zema 2016 A review on swine production system and its status in Ethiopia: challenges and future prospectives. International Journal of Nutrition and Agriculture Research, 3(2): $93 \quad-99$. Wabacha J K, Maribei J M, Mulei C M, Kyule M N, Zessin K H and Oluoch-Kosura W 2004 Characterization of smallholder pig production in Kikuyu Division, central Kenya. Preventive Veterinary Medicine, 63: 183-195

Yeshambel Mekuriaw \& Bimerew Asmare, 2014. Assessment of Pig Production and Constrai- nts in Mecha District, Amhara Region, Northwestern Ethiopia. Adva. Agri., 1-5.https://doi.org/10.1155/2014/329254

Zemelak Goraga, Meskerem Adamu,Seid Ali, Alemayehu Guteta, Mammo Mengesha, Gustavo J. M. M. Lima 2017. Swine Production, Productivity and Breeding Practices in Ethiopia. International Invention Journal of Agricultural and Soil Science (ISSN: 2408-7254) Vol. 5(2) pp. 26-34 